\title{
Concentration-dependent absorption and emission behaviour of sulforhodamine B in ethylene glycol
}

\author{
M. Wittmann and A. Penzkofer \\ Naturwissenschaftliche Fakultät II - Physik, Universität Regensburg, W-8400 Regensburg, Germany
}

Received 28 December 1992

\begin{abstract}
Absorption cross-section spectra, refractive index dispersions, and fluorescence quantum distributions of sulforhodamine $B$ in ethylene glycol are measured in the concentration region between $10^{-5}$ and $0.5 \mathrm{~mol} / \mathrm{dm}^{3}$. The fluorescence quantum yields are separated into monomer and closely spaced pair contributions. The absorption and stimulated emission cross-section spectra of the monomers and closely spaced pairs are resolved.
\end{abstract}

\section{Introduction}

The dye sulforhodamine B (also called Kiton Red 620, Kiton Red S, and Xylene Red B [1], structural formula is shown in fig. 1 ) is a widely used laser dye in the yellow and red spectral region (see refs. [1-5] and references therein). It has been applied to generate femtosecond pulses in passive mode-locked $[6,7]$ lasers and it served as gain medium in laser amplifiers for femtosecond rhodamine $6 \mathrm{G}$ dye lasers [8-11].

The related dye sulforhodamine $B$ monosodium salt $\left(-\mathrm{SO}_{3} \mathrm{H}\right.$ group of sulforhodamine $\mathrm{B}$ is replaced by $-\mathrm{SO}_{3} \mathrm{Na}$. dye also called Kiton Red S [12] or Kiton Red 620 [4]) is similarly applied as laser dye in single-mode lasers [13], single-mode laser amplifiers [14] and hybridly mode-locked femtosecond lasers [15,16].

Photophysical and photochemical properties of sulforhodamine B are reported in ref. [17]. Triplet extinction coefficients of sulforhodamine $B$ in ethanol are given in ref. [18]. Absorption and emission spectroscopic studies on sulforhodamine B monosodium salt have been performed in the solvents ethanol [12] and trifluoroethanol [19]. The photodecomposition behaviour of sulforhodamine B monosodium salt is analysed in ref. [20].

In dye lasers applying free-flowing jet streams for the gain medium high dye concentrations are needed to achieve sufficient gain. A knowledge of the absorption and emission spectroscopic behaviour of the laser dyes at high concentrations is necessary for a detailed understanding of the laser performance.

In this paper absorption spectra, refractive index spectra, and fluorescence quantum distribution spectra are measured for a series of differently concentrated sulforhodamine B solutions in ethylene glycol (ethylene glycol is the solvent of choice when dye jets are used in the lasers ). The concentration-dependent changes of the absorption spectra and fluorescence quantum distributions are analysed. Applying a closely spaced pair aggregation concept [21-23] the mole fraction of molecules in closely spaced pairs versus concentration is determined from the concentration-dependent absorption changes, and the monomer and closely spaced pair absorption crosssection spectra are separated. The fluorescence quantum yields and fluorescence quantum distributions of the monomers and closely spaced pairs are singled out by using the concept of Förster-type energy transfer $[23,24]$. The stimulated emission cross-section spectra of the monomers and closely spaced pairs are calculated from the corresponding absorption crosssection spectra and fluorescence quantum distributions $[22,25-28]$. 


\section{Experiments}

The laser grade dye sulforhodamine B was purchased from Lambda Physik. It was used without further purification. A thin plate chromatographic analysis (TLC plate silica gel 60 and methanol) gave no indication of any impurities.

The absorption cross-section spectra at low dye concentration up to $2 \times 10^{-2} \mathrm{~mol} / \mathrm{dm}^{3}$ were determined by transmission measurements using a conventional spectrophotometer (Beckman ACTA M4). The dye solutions were kept in fused silica cells of thicknesses down to $10 \mu \mathrm{m}$. For dye concentrations in the range between 0.1 and $0.5 \mathrm{~mol} / \mathrm{dm}^{3}$ the $\mathrm{ab}$ sorption cross-section spectra were determined by reflection measurements of p-polarized light (electric field strength in plane of incidence) at the generalized Brewster angle [29].

The fluorescence spectra were measured using front-face illumination in a self-assembled spectrofluorimeter [28]. A tungsten lamp spectrally filtered with an interference filter centered at $\lambda_{\mathrm{pu}}=550 \mathrm{~nm}$ was used as excitation source. The backward emitted fluorescence light was collected, directed to a spectrometer, and registered with a diode array system. The backward fluorescence detection minimizes the fluorescence reabsorption of the highly concentrated dye solutions. The determination of the fluorescence quantum distribution $E(\lambda)\left(\mathrm{nm}^{-1}\right)$ and of the fluorescence quantum yield $\phi_{\mathrm{F}}=\int_{\mathrm{em}} E(\lambda) \mathrm{d} \lambda$ from the measured fluorescence signal $S(\lambda)$ is described in ref. [28]. Absolute values of $E(\lambda)$ and $\phi_{\mathrm{F}}$ are determined by using the dye rhodamine 101 in ethanol as reference dye (fluorescence quantum yield $\phi_{\mathrm{R}} \approx 0.98$ [ 30 33 ]). Up to a concentration of $0.1 \mathrm{~mol} / \mathrm{dm}^{3}$ dichroitic polarizers in the excitation path (vertical orientation) and detection path (orientation under an angle of $54.74^{\circ}$ to the vertical axis) were used to get fluorescence signals independent of molecular reorientation [34,35]. For higher dye concentrations the polarizers were removed in the probe and reference measurements in order to increase the light throughput. In this case the fluorescence emission of the probe and reference sample are practically isotropic polarized since for the reference dye the molecular reorientation time $\tau_{\mathrm{or}, \mathrm{R}}$ is short compared to the fluorescence lifetime $\tau_{F, R}\left(\tau_{o r, R} \approx 300\right.$ ps [36], $\left.\tau_{\mathrm{F}, \mathrm{R}} \approx 5.0 \mathrm{~ns}\right)$ and for the highly concentrated sulfo- rhodamine B solutions a fast reorientation of the excited molecules takes place by Förster-type energy transfer [22].

\section{Results}

Absorption cross-section spectra of sulforhodamine $B$ in ethylene glycol are shown in fig. 1 . The solid curve 1 was measured for a dye concentration of $10^{-4}$ $\mathrm{mol} / \mathrm{dm}^{3}$. Up to $10^{-3} \mathrm{~mol} / \mathrm{dm}^{3}$ no concentration dependence of the absorption cross-section spectrum was observed. The dashed curve 4 of fig. 1 belongs to a dye concentration of $0.5 \mathrm{~mol} / \mathrm{dm}^{3}$. The spectrum is broadened, the absorption peak at $564 \mathrm{~nm}$ is reduced, and the shoulder at $530 \mathrm{~nm}$ is more pronounced. The curves 2 and 3 show the absorption

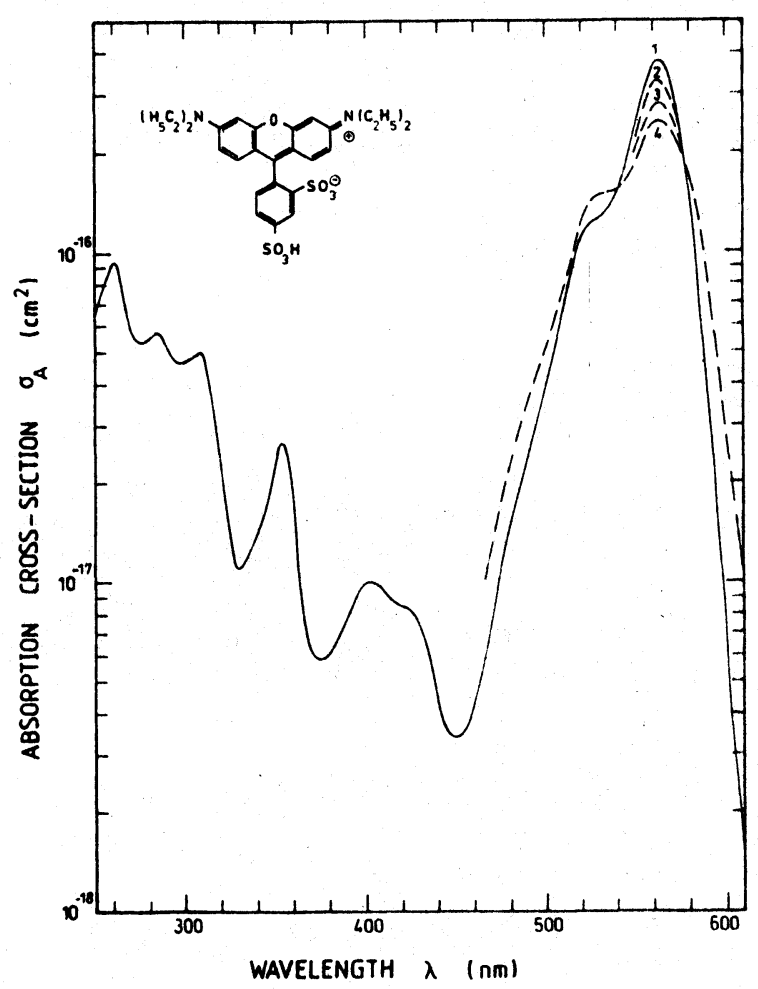

Fig. 1. Absorption cross-section spectra of sulforhodamine B in ethylene glycol at room temperature. The dye concentrations are (1) $C=10^{-4} \mathrm{~mol} / \mathrm{dm}^{3}$, (2) $0.1 \mathrm{~mol} / \mathrm{dm}^{3}$. (3) $0.2 \mathrm{~mol} / \mathrm{dm}^{3}$, and (4) $0.5 \mathrm{~mol} / \mathrm{dm}^{3}$. The structural formula of sulforhodamine $B$ is inserted. 
cross-sections around the $S_{0}-S_{1}$ absorption peak for concentrations of $0.1 \mathrm{~mol} / \mathrm{dm}^{3}$ and $0.2 \mathrm{~mol} / \mathrm{dm}^{3}$, respectively. The absorption spectra have isosbestic points (absorption cross-section independent of concentration ) at $541 \mathrm{~nm}$ and $577 \mathrm{~nm}$. The absorption cross-section $\sigma_{\mathrm{A}}\left(\mathrm{cm}^{2}\right)$ is related to the molar decadic extinction coefficient $\epsilon_{\mathrm{A}}\left(\mathrm{dm}^{3} / \mathrm{mol} \mathrm{cm}\right)$ by $\epsilon_{\mathrm{A}}=\sigma_{\mathrm{A}} N_{\mathrm{A}} / 1000 \ln (10)$ where $N_{\mathrm{A}}=6.022045 \times 10^{23}$ $\mathrm{mol}^{-1}$ is the Avogadro constant.

The mutual interaction of dye molecules at high concentrations is responsible for the concentration dependent absorption cross-section changes [28]. At concentrations of $C=0.1 \mathrm{~mol} / \mathrm{dm}^{3}$ and $C=0.5 \mathrm{~mol} /$ $\mathrm{dm}^{3}$ the average distance $d=\left(N_{\mathrm{A}} C\right)^{-1 / 3}$ between two dye molecules is estimated to be $2.55 \mathrm{~nm}$ and 1.49 $\mathrm{nm}$, respectively.

The concentration-dependent absorption crosssection spectra $\sigma_{\mathrm{A}}(\lambda, C)$ are composed of monomer $\sigma_{\mathrm{A}, \mathrm{M}}(\lambda)$ and closely spaced pair contributions $\sigma_{\mathrm{A}, \mathrm{P}}(\lambda)$ $[21,22]$, i.e. $\sigma_{\mathrm{A}}(\lambda, C)=x_{\mathrm{M}} \sigma_{\mathrm{A}, \mathrm{M}}(\lambda)+x_{\mathrm{P}} \sigma_{\mathrm{A}, \mathrm{P}}(\lambda)$, where $x_{M}$ is the mole fraction of monomers and $x_{P}=1-x_{M}$ is the fraction of molecules in closely spaced pairs. In fig. 2 the ratio

$\frac{\sigma_{\mathrm{A}}}{\sigma_{\mathrm{A}, \mathrm{M}}}=x_{\mathrm{M}}+x_{\mathrm{P}} \frac{\sigma_{\mathrm{A}, \mathrm{P}}}{\sigma_{\mathrm{A}, \mathrm{M}}}=1-x_{\mathrm{P}}\left(1-\frac{\sigma_{\mathrm{A}, \mathrm{P}}}{\sigma_{\mathrm{A}, \mathrm{M}}}\right)$

is plotted versus concentration for $\lambda=564 \mathrm{~nm}$. The circles represent experimental $\sigma_{\mathrm{A}} / \sigma_{\mathrm{A} . \mathrm{M}}$ points derived from fig. 1 , where $\sigma_{\mathrm{A} . \mathrm{M}}(\lambda)$ is given by curve 1 in fig. 1 .

The fraction $x_{\mathrm{p}}$ of molecules in closely spaced pairs at concentration $C$ is given by [21-24]

$x_{\mathbf{P}}=1-\exp \left(-V_{1} N_{\mathrm{A}} C\right)$,

where $V_{\mathrm{I}}$ is the interaction volume of a closely spaced pair. In fig. 2 some $\sigma_{\mathrm{A}} / \sigma_{\mathrm{A}, \mathrm{M}}$ curves are shown for selected pairs of $\sigma_{\mathrm{A}, \mathrm{P}} / \sigma_{\mathrm{A}, \mathrm{M}}$ and $V_{\mathrm{I}}$ values which pass through the experimental $\sigma_{\mathrm{A}} / \sigma_{\mathrm{A}, \mathrm{M}}$ point at $C=0.5$ $\mathrm{mol} / \mathrm{dm}^{3}$. The experimental points are best fitted by the pair $\sigma_{\mathrm{A}, \mathrm{P}} / \sigma_{\mathrm{A}, \mathrm{M}}=0.63$ and $V_{\mathrm{I}}=8.8 \mathrm{~nm}^{3}$. The resulting mole fraction of molecules in closely spaced pairs versus concentration is plotted in fig. 3. At $C=0.5 \mathrm{~mol} / \mathrm{dm}^{3}$ the fraction of molecules in closely spaced pairs is $x_{\mathrm{P}} \approx 0.93$.

The closely spaced pair absorption cross-section spectrum $\sigma_{\mathrm{A}, \mathrm{P}}(\lambda)$ is derived from the curves 4 $\left(\sigma_{\mathrm{A}}(\lambda)\right)$ and $1\left(\sigma_{\mathrm{A}, \mathrm{M}}(\lambda)\right)$ of fig. 1 by application of

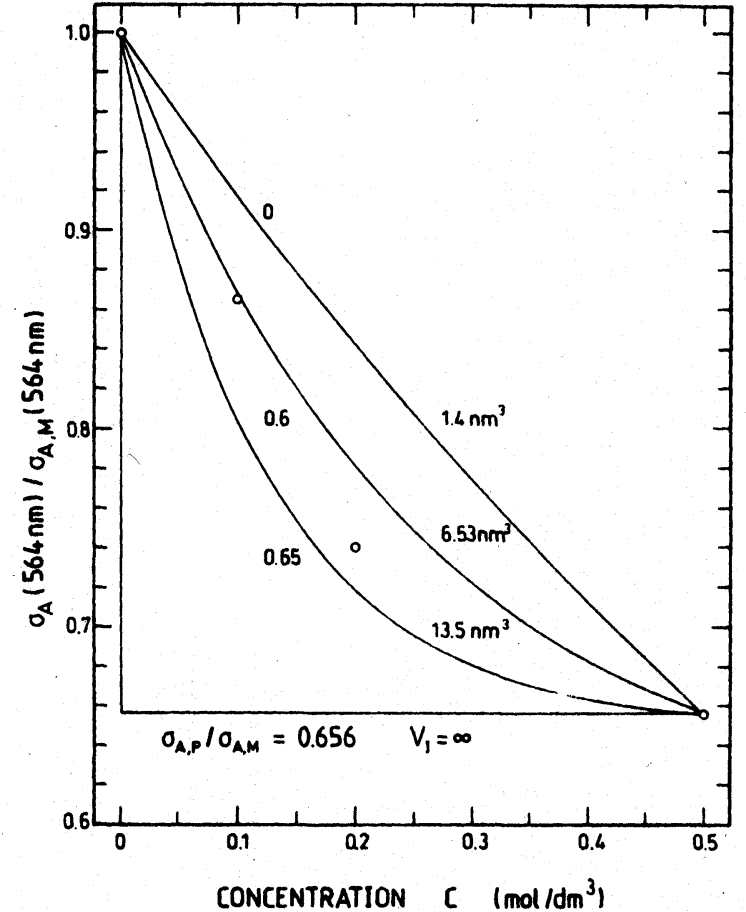

Fig. 2. Absorption cross-section ratio $\sigma_{\mathrm{A}} / \sigma_{\mathrm{A}, \mathrm{M}}$ at $\lambda=564 \mathrm{~nm}$ versus concentration. Circles are experimental points derived from fig. 1. The curves are calculated (eq. (1)) using the parameters listed in the figure.

eq. (1) $\left(x_{\mathrm{P}}=0.93\right), \sigma_{\mathrm{A}, \mathrm{M}}(\lambda)$ and $\sigma_{\mathrm{A}, \mathrm{P}}(\lambda)$ are displayed in fig. 4.

Besides the absorption cross-sections, the refractive indices are determined simultaneously by the reflectance measurements at high dye concentration [29]. The refractive index dispersions $n(\lambda, C)$ of 0.2 and 0.5 molar solutions of sulforhodamine $B$ in ethylene glycol are displayed by the dashed and solid curves in fig. 5 , respectively. The dash-dotted curve shows the refractive index dependence $n_{s}(\lambda)$ of the solvent ethylene glycol [37].

The experimental fluorescence quantum distributions $E(i)$ for a series of dye concentrations are displayed by the solid curves in fig. 6 , and the experimental fluorescence quantum yields, $\phi_{\mathrm{F}}=\int_{\mathrm{em}} E(\lambda) \mathrm{d} \lambda$, are shown by the circles in fig. 7. Up to about $4 \times 10^{-3}$ $\mathrm{mol} / \mathrm{dm}^{3} E(\lambda)$ and $\phi_{\mathrm{F}}$ are independent of concentration. The monomer fluorescence quantum yield at low concentrations is $\phi_{\mathrm{F}, 0} \approx 0.89$. In the range between $10^{-2}$ and $0.2 \mathrm{~mol} / \mathrm{dm}^{3}$ the fluorescence quantum yield drops strongly with rising dye concentration. 


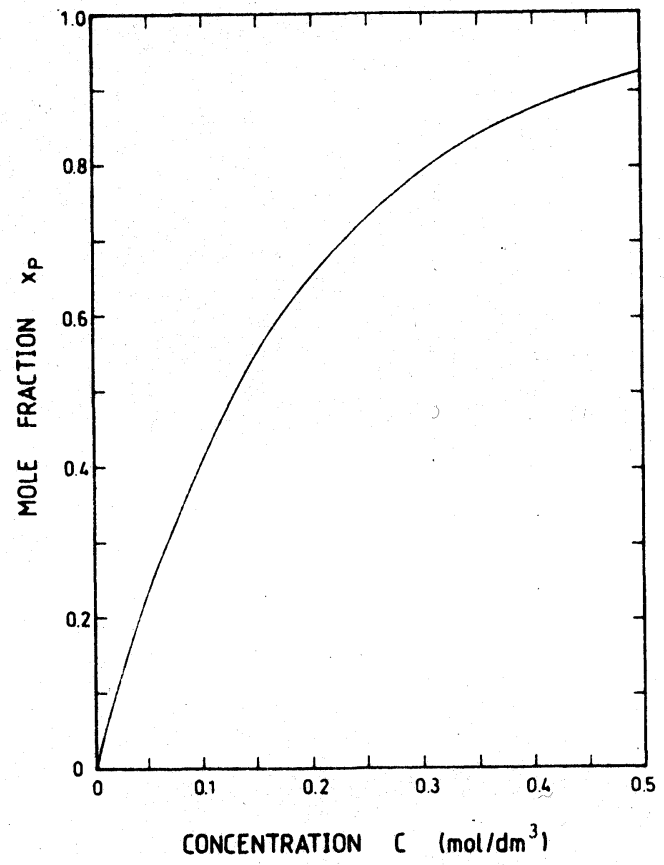

Fig. 3. Mole fraction $x_{\mathrm{P}}$ of molecules in closely spaced pairs as a function of concentration for sulforhodamine $B$ in ethylene glycol (eq. (2) with $V_{1}=8.8 \mathrm{~nm}^{3}$ ).

The decrease of $E(\lambda)$ and $\phi_{\mathrm{F}}$ with rising concentration is due to the low fluorescence quantum yield of closely spaced pairs and the energy transfer of excited monomers to closely spaced pairs [22-24]. For dye concentrations above $0.3 \mathrm{~mol} / \mathrm{dm}^{3}$ the fluorescence quantum yield is approximately constant having a value of $\phi_{\mathrm{F}}\left(\geqslant 0.3 \mathrm{~mol} / \mathrm{dm}^{3}\right) \approx 0.0075 \pm 0.001$. In this high concentration region the closely spaced pair fluorescence dominates.

The fluorescence quantum yield $\phi_{\mathrm{F}}(C)$ is composed of monomer $\phi_{\mathrm{M}}(C)$ and closely spaced pair $\phi_{\mathrm{P}}(C)$ contributions according to

$\phi_{\mathrm{F}}(C)=\phi_{\mathrm{M}}(C)+\phi_{\mathrm{P}}(C)$

Without energy transfer the quantum yields would be given by [22]

$\phi_{M}^{\prime}=x_{M}^{\prime} \phi_{\mathbf{F}, 0}$,

$\phi_{\mathrm{P}}^{\prime}=x_{\mathrm{P}}^{\prime} \phi_{\mathrm{F}, 1}$,

where $\phi_{F, 0}$ and $\phi_{F, 1}$ are the fluorescence quantum yields at $x_{\mathrm{P}}=0$ and $x_{\mathrm{P}}=1$, respectively. $x_{M}^{\prime}$ and $x_{\mathrm{P}}^{\prime}$ are reduced mole fractions given by

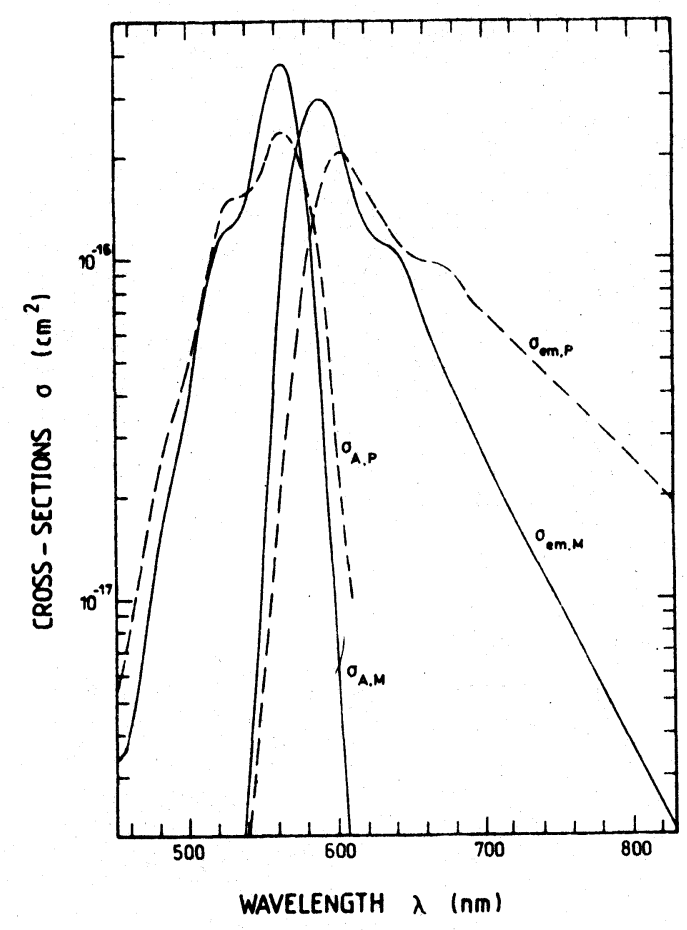

Fig. 4. Absorption cross-section spectra $\sigma_{\mathrm{A}, \mathrm{M}}$ and $\sigma_{\mathrm{A}, \mathrm{P}}$ and stimulated emission cross-section spectra $\sigma_{\mathrm{em}, \mathrm{M}}$ and $\sigma_{\mathrm{em} . \mathrm{P}}$ for monomers $(M)$ and closely spaced pairs $(P)$ of sulforhodamine $B$ in ethylene glycol.

$x_{\mathrm{M}}^{\prime}=\frac{x_{\mathrm{M}} \sigma_{\mathrm{A}, \mathrm{M}}\left(\lambda_{\mathrm{pu}}\right)}{x_{\mathrm{M}} \sigma_{\mathrm{A}, \mathrm{M}}\left(\lambda_{\mathrm{pu}}\right)+x_{\mathrm{P}} \sigma_{\mathrm{A}, \mathrm{P}}\left(\lambda_{\mathrm{pu}}\right)}$

and

$x_{\mathrm{P}}^{\prime}=\frac{x_{\mathrm{P}} \sigma_{\mathrm{A}, \mathrm{P}}\left(\lambda_{\mathrm{pu}}\right)}{x_{\mathrm{M}} \sigma_{\mathrm{A}, \mathrm{M}}\left(\lambda_{\mathrm{pu}}\right)+x_{\mathrm{P}} \sigma_{\mathrm{A}, \mathrm{P}}\left(\lambda_{\mathrm{pu}}\right)}$.

$\lambda_{\mathrm{pu}}$ is the wavelength of the excitation light $\left(\lambda_{\mathrm{pu}}=550\right.$ $\mathrm{nm}$ in our experiments ).

Taking into account the Förster-type energy transfer from excited monomers to closely spaced pairs and the energy back transfer to monomers as well as the energy transfer from excited closely spaced pairs to monomers and the corresponding energy back transfer, the quantum yield of fluorescence emission released from monomers $\phi_{M}$ and the quantum yield of fluorescence emission released from closely spaced pairs $\phi_{\mathrm{p}}$ become

$$
\begin{aligned}
\phi_{M} & =\frac{\phi_{F, 0}}{1+x_{P}\left(C / C_{0}\right)^{2}\left(1-f_{P, M}\right)} \\
& \times\left(x_{M}^{\prime}+x_{P}^{\prime} f_{P, M}\right)
\end{aligned}
$$




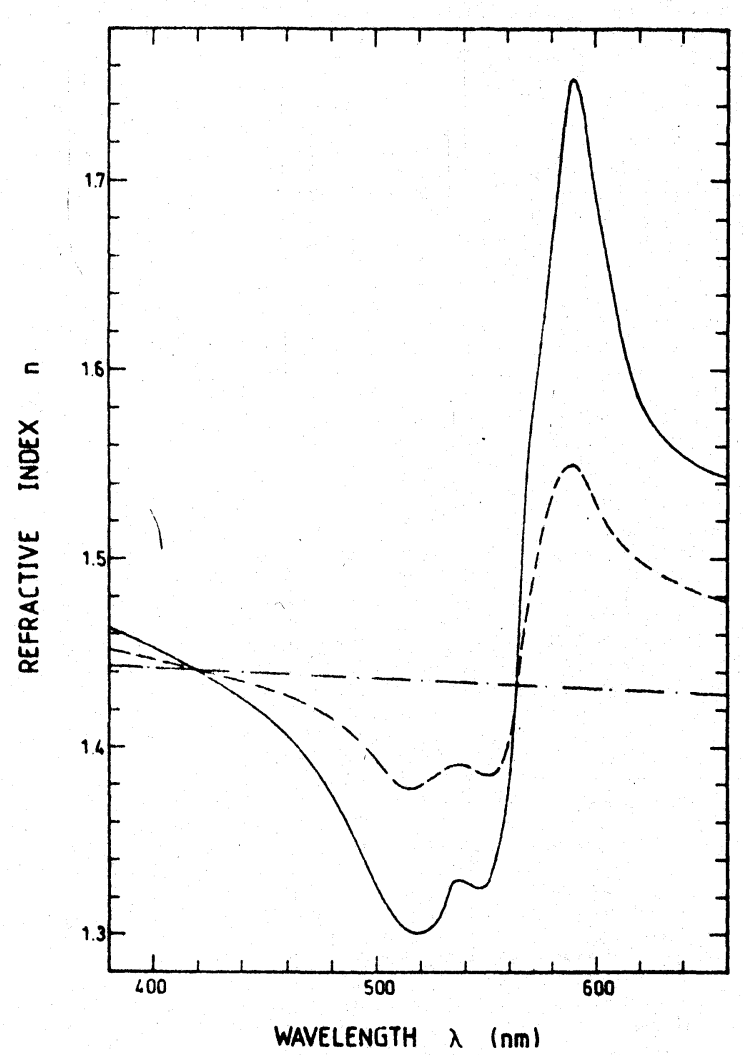

Fig. 5. Refractive index spectra of sulforhodamine $B$ in ethylene glycol at room temperature. Solid curve, concentration $C=0.5$ $\mathrm{mol} / \mathrm{dm}^{3}$. Dashed curve, $C=0.2 \mathrm{~mol} / \mathrm{dm}^{3}$. Dash-dotted curve, solvent ethylene glycol (from ref. [37]).

and

$$
\begin{aligned}
& \phi_{\mathrm{P}}=\phi_{\mathrm{F}, 1}\left(1+\frac{\left(C / C_{0}\right)^{2}\left(1-x_{\mathrm{P}}\right)}{1+\left(C / C_{0}\right)^{2} x_{\mathrm{P}}} \frac{\phi_{\mathrm{F}, 1} \tau_{\mathrm{rad}, \mathrm{P}}}{\phi_{\mathrm{F}, 0} \tau_{\mathrm{rad}, \mathrm{M}}}\right)^{-1} \\
& \times\left(x_{M}^{\prime} \frac{\left(C / C_{0}\right)^{2} x_{P}\left(1-f_{P, M}\right)}{1+\left(C / C_{0}\right)^{2} x_{P}\left(1-f_{P, M}\right)}+x_{P}^{\prime}\right),
\end{aligned}
$$

with

$$
\begin{aligned}
& f_{\mathrm{P}, \mathrm{M}}=\frac{\phi_{\mathrm{F}, 1} \tau_{\mathrm{rad}, \mathrm{P}}}{\phi_{\mathrm{F}, 0} \tau_{\mathrm{rad}, \mathrm{M}}}\left(\frac{C}{C_{0}}\right)^{2}\left(1-x_{\mathrm{P}}\right) \\
& \times\left(1+\frac{\phi_{\mathrm{F}, 1} \tau_{\mathrm{rad}, \mathrm{P}}}{\phi_{\mathrm{F}, 0} \tau_{\mathrm{rad}, \mathrm{M}}}\left(\frac{C}{C_{0}}\right)^{2}\left(1-x_{\mathrm{P}}\right)\right)^{-1} .
\end{aligned}
$$

Eqs. (8)-(10) are derived in the Appendix. $C_{0}$ is the Förster-type critical transfer concentration. $\tau_{\text {rad,M }}$ and

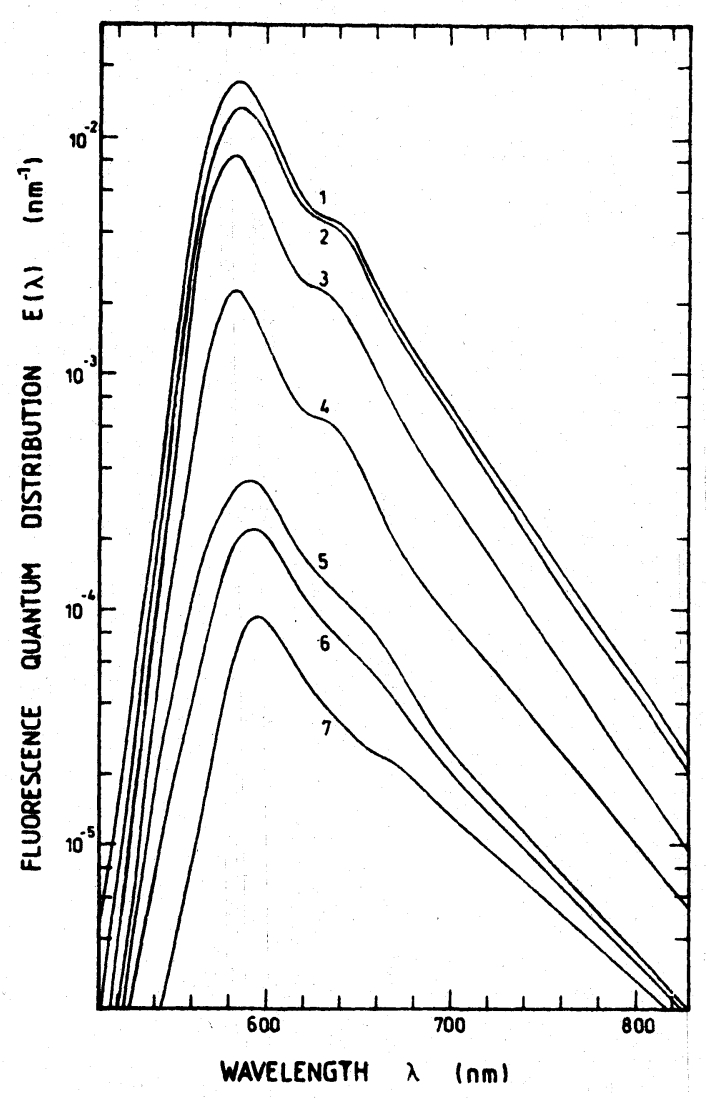

Fig. 6. Fluorescence quantum distributions $E(\lambda)$ of sulforhodamine $B$ in ethylene glycol for various dye concentrations. (1) $C=10^{-4} \mathrm{~mol} / \mathrm{dm}^{3}$, (2) $10^{-2} \mathrm{~mol} / \mathrm{dm}^{3}$, (3) $2 \times 10^{-2} \mathrm{~mol} / \mathrm{dm}^{3}$, (4) $5 \times 10^{-2} \mathrm{~mol} / \mathrm{dm}^{3}$, (5) $0.1 \mathrm{~mol} / \mathrm{dm}^{3}$, (6) $0.2 \mathrm{~mol} / \mathrm{dm}^{3}$, and (7) $0.5 \mathrm{~mol} / \mathrm{dm}^{3}$. Curve 1 is only determined by monomers and curve 7 is only determined by closely spaced pairs.

$\tau_{\text {rad.P }}$ are radiative $S_{1}$-state lifetimes of the monomers and closely spaced pairs, respectively.

The unknown parameters $\phi_{\mathrm{F}, 1}$ and $C_{0}$ are determined by fitting eq. (3) with the components of eqs. $(8)$ and $(9)$ to the experimental $\phi_{\mathrm{F}}(C)$ points in fig. 7. $\tau_{\text {rad,M }}$ and $\tau_{\text {rad,P }}$ are determined below (eq. (14)). The solid fit curve in fig. 7 gives $\phi_{\mathrm{F}, 1}=0.0075$ and $C_{0}=7 \times 10^{-3} \mathrm{~mol} / \mathrm{dm}^{3}$. The corresponding monomer $\phi_{M}(C)$ and closely spaced pair contributions $\phi_{\mathrm{P}}(C)$ are shown by the dashed curves in fig. 7. The dash-dotted curves in fig. 7 represent $\phi_{M}^{\prime}$ and $\phi_{\mathrm{P}}^{\prime}$.

The fluorescence quantum distribution $E(\lambda, C)$ is composed of monomeric, $E_{\mathrm{M}}(\lambda, C)$, and closely spaced pair, $E_{\mathrm{P}}(\lambda, C)$, contributions according to

$E(\lambda, C)=E_{\mathrm{M}}(\lambda, C)+E_{\mathrm{P}}(\lambda, C)$. 


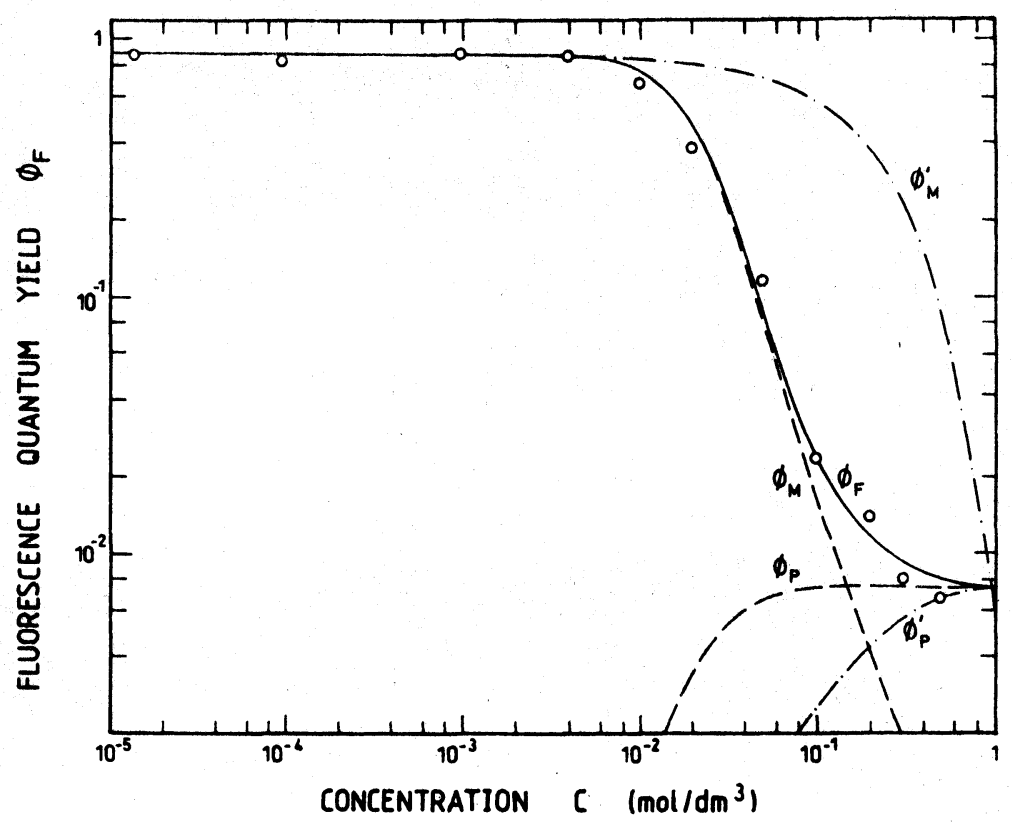

Fig. 7. Fluorescence quantum yield $\phi_{\mathrm{F}}$ of sulforhodamine $B$ in ethylene glycol versus concentration. Circles are experimental points. The solid curve is the fitted $\phi_{\mathrm{F}}(C)$ curve using $x_{\mathrm{P}}$ of fig. $3, \sigma_{\mathrm{A}, \mathrm{M}}\left(\lambda_{\mathrm{pu}}\right)$ and $\sigma_{\mathrm{A}, \mathrm{P}}\left(\lambda_{\mathrm{pu}}\right)$ of fig. $4, C_{0}=7 \times 10^{-3} \mathrm{~mol} / \mathrm{dm}^{3}$ and $\phi_{\mathrm{F}, 1}=0.0075$. The dashed curves show the contributions $\phi_{M}(C)($ eq. $(8))$ and $\phi_{p}(C)$ (eq. (9)), while the dash-dotted curves represent $\phi_{M}^{\prime}(C)$ (eq. (4)) and $\phi_{p}^{\prime}(C)$ (eq. (5)).

The monomeric fluorescence quantum distribution is given by

$E_{\mathrm{M}}(\lambda, C)=\frac{\phi_{\mathrm{M}}(C)}{\phi_{\mathrm{F}, 0}} E(\lambda, 0)$,

where $E(\lambda, 0)$ is the fluorescence quantum distribution at low dye concentration (curve 1 in fig. 6 ). The closely spaced pair fluorescence quantum distribution $E_{\mathrm{P}}(\lambda, C)$ is obtained from eqs. (11) and (12) to be

$E_{\mathrm{P}}(\lambda, C)=E(\lambda, C)-\frac{\phi_{\mathrm{M}}(C)}{\phi_{\mathrm{F}, 0}} E(\lambda, 0)$.

For $C \gtrsim 0.3 \mathrm{~mol} / \mathrm{dm}^{3}$ the monomer fluorescence contribution $\phi_{\mathrm{M}}(C)$ to $\phi_{\mathrm{F}}(C)$ becomes negligible and $E_{\mathrm{p}}(\lambda, C)$ becomes approximately equal to $E(\lambda, C)$. The curve 7 in fig. 6 represents the closely spaced pair fluorescence quantum distribution at $C=0.5 \mathrm{~mol} /$ $\mathrm{dm}^{3}$.

The radiative lifetimes of the monomers, $\tau_{\mathrm{rad}, \mathrm{M}}$, and closely spaced pairs, $\tau_{\text {rad,P, }}$, are given by the StricklerBerg formula $[26,27](i=\mathrm{M}$ or $\mathrm{P})$

$$
\begin{aligned}
& \frac{1}{\tau_{\text {rad }, i}}=8 \pi c_{0} \frac{\int_{\mathrm{em}} E_{i}(\lambda) \mathrm{d} \lambda}{\int_{\mathrm{em}} E_{i}(\lambda) \lambda^{3} n^{-3}(\lambda) \mathrm{d} \lambda} \\
& \quad \times \int_{\mathrm{abs}} \frac{\sigma_{\mathrm{A}, i}(\lambda)}{\lambda n(\lambda)} \mathrm{d} \lambda,
\end{aligned}
$$

where $c_{0}$ is the velocity of light in vacuum and $n(\lambda)$ is the refractive index of the solution at wavelength $\lambda$. The integration em extends over the $S_{1}-S_{0}$ fluorescence band and the integration abs extends over the $\mathrm{S}_{0}-\mathrm{S}_{1}$ absorption band. The calculated values of $\tau_{\mathrm{rad}, \mathrm{M}}$ for $C \rightarrow 0$ and $\tau_{\text {rad, }}$ for $C=0.5 \mathrm{~mol} / \mathrm{dm}^{3}$ are listed in table 1 .

In the case of single exponential decay of the $S_{1}$ state level population of the monomers and the closely spaced pairs, the fluorescence lifetimes are related to the radiative lifetimes by $\tau_{F, M}=\tau_{F}(C=0)=\phi_{F, 0} \tau_{\text {rad, } M}$ and $\tau_{F, P}=\tau_{F}\left(x_{P}=1\right)=\phi_{F, 1} \tau_{\text {rad,P. }}$. The obtained $\tau_{F, M}$ and $\tau_{F . P}$ values are listed in table 1 .

The stimulated emission cross-section spectra $\sigma_{\text {em.M }}$ of the monomers and $\sigma_{\text {em.P }}$ of the closely spaced pairs are determined by the corresponding absorption cross-section spectra, $\sigma_{\mathrm{A}, \mathrm{M}}$ and $\sigma_{\mathrm{A}, \mathrm{P}}$, and the fluores- 
Table 1

Spectroscopic data of sulforhodamine B in ethylene glycol

\begin{tabular}{ll}
\hline Parameter & Value \\
\hline$C_{0}$ & $7 \times 10^{-3} \mathrm{~mol} / \mathrm{dm}^{3}$ \\
$V_{\mathrm{I}}$ & $8.8 \mathrm{~nm}^{3}$ \\
$\int_{\mathrm{abs}} \sigma_{\mathrm{A}, \mathrm{M}}(\tilde{\nu}) \mathrm{d} \tilde{\nu}$ & $5.85 \times 10^{-13} \mathrm{~cm}$ \\
$\int_{\mathrm{Abs}} \sigma_{\mathrm{A}, \mathrm{P}}(\tilde{\nu}) \mathrm{d} \tilde{\nu}$ & $5.5 \times 10^{-13} \mathrm{~cm}$ \\
$\int_{\mathrm{em}} \sigma_{\mathrm{em}, \mathrm{M}}(\tilde{\nu}) \mathrm{d} \tilde{\nu}$ & $5.2 \times 10^{-13} \mathrm{~cm}$ \\
$\int_{\mathrm{em}} \sigma_{\mathrm{em}, \mathrm{P}}(\tilde{\nu}) \mathrm{d} \tilde{\nu}$ & $5.2 \times 10^{-13} \mathrm{~cm}$ \\
$\tau_{\mathrm{rad}, \mathrm{M}}$ & $4.6 \mathrm{~ns}$ \\
$\tau_{\mathrm{rad}, \mathrm{P}}$ & $4.1 \mathrm{~ns}$ \\
$\tau_{\mathrm{F}, \mathrm{M}}$ & $4.1 \mathrm{~ns}$ \\
$\tau_{\mathrm{F}, \mathrm{P}}$ & $32 \mathrm{ps}$ \\
$\phi_{\mathrm{F}, 0}$ & 0.89 \\
$\phi_{\mathrm{F}, \mathrm{I}}$ & 0.0075 \\
\hline
\end{tabular}

cence quantum distributions, $E_{\mathrm{M}}(\lambda)$ and $E_{\mathrm{P}}(\lambda)$, according to the relation $[25-27,38]$

$\sigma_{\mathrm{em}, i}(\lambda)=\frac{\lambda^{4}}{8 \pi n^{2}(\lambda) c_{0} \tau_{\mathrm{rad}, i}} \frac{E_{i}(\lambda)}{\int_{\mathrm{em}} E_{i}(\lambda) \mathrm{d} \lambda}$,

where $i=\mathbf{M}$ for the monomers and $i=\mathbf{P}$ for the closely spaced pairs. In fig. 4 the monomer stimulated emission cross-section spectra $\sigma_{\mathrm{em}, \mathrm{M}}$ for $C \rightarrow 0$ and $\sigma_{\mathrm{em}, \mathrm{P}}$ for $C=0.5 \mathrm{~mol} / \mathrm{dm}^{3}$ are shown

The total integrated absorption cross-sections, $\int_{\text {abs }} \sigma_{\mathrm{A}, i}(\tilde{\nu}) \mathrm{d} \tilde{\nu}$, and the total integrated stimulated emission cross-sections, $\int_{\mathrm{em}} \sigma_{\mathrm{em}, i}(\tilde{\nu}) \mathrm{d} \tilde{\nu}$, are collected in table $1(i=\mathrm{M}, \mathrm{P}, \tilde{\boldsymbol{\nu}}=1 / \lambda)$.

\section{Conclusions}

The concentration dependent absorption and emission spectroscopic behaviour of sulforhodamine $B$ in ethylene glycol has been investigated. The monomer and closely spaced pair absorption and emission spectra have been separated. Up to nearly $10^{-2} \mathrm{~mol} / \mathrm{dm}^{3}$ the closely spaced pair concentration is small and the influences of the closely spaced pairs are weak. Dye concentrations up to $10^{-2} \mathrm{~mol} / \mathrm{dm}^{3}$ may be used in dye laser applications without aggregation drawbacks. In a recent study on femtosecond pulse generation in a passively mode-locked sulforhodamine $B$ dye laser a dye concentration of $3 \times 10^{-3}$ $\mathrm{mol} / \mathrm{dm}^{3}$ (gain jet thickness $100 \mu \mathrm{m}$ ) was applied and pulse durations down to $50 \mathrm{fs}$ around $650 \mathrm{~nm}$ have been achieved [7].

\section{Acknowledgement}

The authors are grateful to Mr. M. Schäffner, Dr. W. Bäumler, and Dr. V. Petrov for fruitful discussions. They thank the Rechenzentrum of the University for allocation of computer time and the Deutsche Forschungsgemeinschaft for financial support.

\section{Appendix}

The reduction of fluorescence quantum yield by Förster-type energy transfer is considered.

The total fluorescence quantum yield $\phi_{\mathrm{F}}$ is composed of quantum yields resulting from emission of excited monomers $\phi_{M}$ and excited closely spaced pairs $\phi_{P}$, i.e. $\phi_{F}=\phi_{M}+o_{P}$ (eq. (3)). The monomer fluorescence quantum yield $\phi_{M}$ is composed of contributions from pump pulse excited monomers $\phi_{M, M}$ and pump pulse excited closely spaced pairs $\phi_{\mathrm{M}, \mathrm{P}}$ (energy transfer from closely spaced pair to monomer). Similarly the closely spaced pair quantum yield $\phi_{\mathrm{P}}$ is composed of contributions from pump pulse excited monomers $\phi_{\mathrm{P} . \mathrm{M}}$ and pump pulse excited closely spaced pairs $\phi_{\mathrm{P}, \mathrm{P}}$. The relations are

$$
\begin{aligned}
& \phi_{M}=\phi_{M, M}+\phi_{M, P}, \\
& \phi_{P}=\phi_{P, M}+\phi_{P, P} .
\end{aligned}
$$

The monomer excited and monomer released fluorescence quantum yield is given by 
$\phi_{\mathrm{M}, \mathrm{M}}=x_{\mathrm{M}}^{\prime} \frac{k_{\mathrm{rad}, \mathrm{M}}}{k_{\mathrm{M}}}$

where $k_{\text {rad.M }}$ is the radiative spontaneous emission rate of the monomer species and $k_{M}$ is the total excited monomer deactivation rate. $k_{\mathrm{M}}$ is composed of low-concentration radiative $\left(k_{\mathrm{rad}, \mathrm{M}}\right)$, low-concentration nonradiative $\left(k_{\mathrm{nr}, \mathrm{M}}\right)$ and concentration-dependent monomer-closely-spaced-pair energy transfer $\left(k_{\mathrm{M}, \mathrm{P}}\right)$ rates. It is

$k_{\mathrm{M}}=k_{\mathrm{rad}, \mathrm{M}}+k_{\mathrm{nr}, \mathrm{M}}+k_{\mathrm{M}, \mathrm{P}}=k_{\mathrm{F}, 0}+k_{\mathrm{M}, \mathrm{P}}$,

where $k_{\mathrm{F}, 0}=k_{\mathrm{rad}, \mathrm{M}}+k_{\mathrm{nr}, \mathrm{M}}$ is the fluorescence decay rate at low concentrations.

The monomer-closely-spaced-pair energy transfer rate $k_{\mathrm{M}, \mathrm{P}}$ is given by

$k_{\mathrm{M}, \mathrm{P}}=k_{\mathrm{ET}, \mathrm{M}} x_{\mathrm{P}} g\left(1-f_{\mathrm{P}, \mathrm{M}}\right)$,

where $k_{\mathrm{ET}, \mathrm{M}}$ is the excited-monomer-ground-state-monomer energy transfer rate. For Förster-type energy transfer it is

$k_{\mathrm{ET}, \mathrm{M}}=k_{\mathrm{F}, 0}\left(C / C_{0, \mathrm{M}}\right)^{2}$,

where $C_{0, \mathrm{M}}$ is the critical monomer dye concentration (for $C=C_{0, \mathrm{M}}$ it is $k_{\mathrm{ET}, \mathrm{M}}=k_{\mathrm{F}, 0}$ ). The product $k_{\mathrm{ET}, \mathrm{M}} x_{\mathrm{P}} g$ determines the energy transfer rate from monomers to closely spaced pairs. $g$ is the ratio of monomer-closelyspaced-pair energy transfer probability to monomer-monomer energy transfer probability. In our calculations (eqs. (8)-(10)) we assume $g=1$. The factor $f_{\mathrm{P}, \mathrm{M}}$ takes into account the fraction of excited closely spaced pairs which transfer their excitation energy back to monomers. The back transfer fraction $f_{\mathrm{P}, \mathrm{M}}$ is given by

$$
\begin{aligned}
f_{\mathrm{P}, \mathrm{M}} & =\frac{k_{\mathrm{ET}, \mathrm{P}} x_{\mathrm{M}} g}{k_{\mathrm{F}, 1}+k_{\mathrm{ET}, \mathrm{P}} x_{\mathrm{M}} g}=\frac{\left(k_{\mathrm{ET}, \mathrm{P}} / k_{\mathrm{F}, 1}\right)\left(1-x_{\mathrm{P}}\right) g}{1+\left(k_{\mathrm{ET}, \mathrm{P}} / k_{\mathrm{F}, 1}\right)\left(1-x_{\mathrm{P}}\right) g}=\frac{\left(k_{\mathrm{F}, 0} / k_{\mathrm{F}, 1}\right)\left(C / C_{0, \mathrm{P}}\right)^{2}\left(1-x_{\mathrm{P}}\right) g}{1+\left(k_{\mathrm{F}, 0} / k_{\mathrm{F}, 1}\right)\left(C / C_{0, \mathrm{P}}\right)^{2}\left(1-x_{\mathrm{P}}\right) g} \\
= & \frac{\left(\phi_{\mathrm{F}, 1} \tau_{\mathrm{rad}, \mathrm{P}} / \phi_{\mathrm{F}, 0} \tau_{\mathrm{rad}, \mathrm{M}}\right)\left(C / C_{0, \mathrm{P}}\right)^{2}\left(1-x_{\mathrm{P}}\right) g}{1+\left(\phi_{\mathrm{F}, 1} \tau_{\mathrm{rad}, \mathrm{P}} / \phi_{\mathrm{F}, 0} \tau_{\mathrm{rad}, \mathrm{M}}\right)\left(C / C_{0, \mathrm{P}}\right)\left(1-x_{\mathrm{P}}\right) g}
\end{aligned}
$$

where

$k_{\mathrm{ET}, \mathrm{P}}=k_{\mathrm{F}, 0}\left(C / C_{0, \mathrm{P}}\right)^{2}$

is the Förster-type energy transfer between closely spaced pairs. We assume $C_{0, \mathrm{P}}=C_{0, \mathrm{M}}=C_{0}$ in our calculations (eqs. $(8)-(10)) \cdot k_{\mathrm{F}, 1}=k_{\mathrm{F}}\left(x_{\mathrm{D}}=1\right)$ is the excited closely spaced pair relaxation rate at high concentrations $\left(x_{\mathrm{D}} \rightarrow 1\right) . \phi_{\mathrm{F}, 0}=k_{\mathrm{rad}, \mathrm{M}} / k_{\mathrm{F}, 0}$ is the fluorescence quantum yield at low concentration. $\phi_{\mathrm{F}, 1}=\phi_{\mathrm{F}}\left(x_{\mathrm{D}}=1\right)=k_{\mathrm{rad}, \mathrm{P}} / k_{\mathrm{F}, 1}$ is the corresponding high concentration fluorescence quantum yield.

Insertion of the eqs. (A.4)-(A.7) into (A.3) leads to

$\phi_{\mathrm{M}, \mathrm{M}}=\frac{x_{\mathrm{M}}^{\prime} \phi_{\mathrm{F}, 0}}{1+x_{\mathrm{P}} g\left(C / C_{0, \mathrm{M}}\right)^{2}\left(1-f_{\mathrm{P}, \mathrm{M}}\right)}$.

The closely spaced pair excited and monomer released fluorescence quantum yield $\phi_{M, P}$ is given by

$\phi_{\mathrm{M}, \mathrm{P}}=x_{\mathrm{P}}^{\prime} f_{\mathrm{P}, \mathrm{M}} \frac{k_{\mathrm{rad}, \mathrm{M}}}{k_{\mathrm{M}}}=\frac{x_{\mathrm{P}}^{\prime} f_{\mathrm{P}, \mathrm{M}} \phi_{\mathrm{F}, 0}}{1+x_{\mathrm{P}} g\left(C / C_{0, \mathrm{M}}\right)^{2}\left(1-f_{\mathrm{P}, \mathrm{M}}\right)}$.

The total monomer released fluorescence quantum yield $\phi_{M}$ is according to eq. (A.1)

$$
\phi_{\mathrm{M}}=\frac{\phi_{\mathrm{F}, 0}}{1+x_{\mathrm{P}} g\left(C / C_{0, M}\right)^{2}\left(1-f_{\mathrm{P}, \mathrm{M}}\right)}\left(x_{\mathrm{M}}^{\prime}+x_{\mathrm{P}}^{\prime} f_{\mathrm{P}, \mathrm{M}}\right)
$$

The monomer excited and closely spaced pair released fluorescence quantum yield $\phi_{\mathrm{P}, \mathrm{M}}$ is given by 
$\phi_{\mathrm{P}, \mathrm{M}}=x_{\mathrm{M}}^{\prime} \frac{k_{\mathrm{M}, \mathrm{P}}}{k_{\mathrm{M}}} \frac{k_{\mathrm{rad}, \mathrm{P}}}{k_{\mathrm{P}}}=x_{\mathrm{M}}^{\prime} \frac{k_{\mathrm{M}, \mathrm{P}}}{k_{\mathrm{F}, 0}+k_{\mathrm{M}, \mathrm{P}}} \frac{k_{\mathrm{rad}, \mathrm{P}}}{k_{\mathrm{F}, 1}+k_{\mathrm{P}, \mathrm{M}}}=x_{\mathrm{M}}^{\prime} \frac{k_{\mathrm{M}, \mathrm{P}} / k_{\mathrm{F}, 0}}{1+k_{\mathrm{M}, \mathrm{P}} / k_{\mathrm{F}, 0}} \frac{\phi_{\mathrm{F}, 1}}{1+k_{\mathrm{P}, \mathrm{M}} / k_{\mathrm{F}, 1}}$.

The closely spaced pair to monomer energy transfer rate is

$k_{\mathrm{P}, \mathrm{M}}=k_{\mathrm{ET}, \mathrm{P}} x_{\mathrm{M}} g\left(1-f_{\mathrm{M}, \mathrm{P}}\right)$.

$f_{M, P}$ is the fraction of monomers returning to closely spaced pairs by energy back transfer. $f_{M, P}$ is given by

$f_{\mathrm{M}, \mathrm{P}}=\frac{k_{\mathrm{ET}, \mathrm{M}} x_{\mathrm{P}} g}{k_{\mathrm{F}, 0}+k_{\mathrm{ET}, \mathrm{M}} x_{\mathrm{P}} g}=\frac{\left(k_{\mathrm{ET}, \mathrm{M}} / k_{\mathrm{F}, 0}\right) x_{\mathrm{P}} g}{1+\left(k_{\mathrm{ET}, \mathrm{M}} / k_{\mathrm{F}, 0}\right) x_{\mathrm{P}} g}=\frac{\left(C / C_{0, \mathrm{M}}\right)^{2} x_{\mathrm{P}} g}{1+\left(C / C_{0, \mathrm{M}}\right)^{2} x_{\mathrm{P}} g}$.

Insertion of eqs. (A.5), (A.6), (A.13) and (A.14) into eq. (A.12) gives

$\phi_{\mathrm{P}, \mathrm{M}}=x_{\mathrm{M}}^{\prime} \frac{\left(C / C_{0, \mathrm{M}}\right)^{2} x_{\mathrm{P}} g\left(1-f_{\mathrm{P}, \mathrm{M}}\right)}{1+\left(C / C_{0, \mathrm{M}}\right)^{2} x_{\mathrm{P}} g\left(1-f_{\mathrm{P}, \mathrm{M}}\right)} \frac{\phi_{\mathrm{F}, 1}}{1+\left(C / C_{0, \mathrm{P}}\right)^{2} x_{\mathrm{M}} g\left(1-f_{\mathrm{M}, \mathrm{P}}\right) \phi_{\mathrm{F}, 1} \tau_{\mathrm{rad}, \mathrm{P}} / \phi_{\mathrm{F}, 0} \tau_{\mathrm{rad}, \mathrm{M}}}$

The closely spaced pair excited and released fluorescence quantum yield $\phi_{\mathrm{P}, \mathrm{P}}$ is described by

$$
\begin{aligned}
\phi_{\mathrm{P}, \mathrm{P}} & =x_{\mathrm{P}}^{\prime} \frac{k_{\mathrm{rad}, \mathrm{P}}}{k_{\mathrm{F}, 1}+k_{\mathrm{P}, \mathrm{M}}}=x_{\mathrm{P}}^{\prime} \frac{\phi_{\mathrm{F}, 1}}{1+k_{\mathrm{P}, \mathrm{M}} / k_{\mathrm{F}, 1}} \\
& =x_{\mathrm{P}}^{\prime} \frac{\phi_{\mathrm{F}, 1}}{1+\left(C / C_{0, \mathrm{P}}\right)^{2} x_{\mathrm{M}} g\left(1-f_{\mathrm{M}, \mathrm{P}}\right) \phi_{\mathrm{F}, 1} \tau_{\mathrm{rad}, \mathrm{P}} / \phi_{\mathrm{F}, 0} \tau_{\mathrm{rad}, \mathrm{M}}} .
\end{aligned}
$$

The total closely spaced pair released fluorescence quantum yield is obtained by insertions of eqs. (A.15) and (A.16) into (A.2):

$\phi_{\mathrm{P}}=\phi_{\mathrm{F}, 1}\left(1+\frac{\left(C / C_{0, \mathrm{P}}\right)^{2} x_{\mathrm{M}} g}{1+\left(C / C_{0, \mathrm{M}}\right)^{2} x_{\mathrm{P}} g} \frac{\phi_{\mathrm{F}, 1} \tau_{\mathrm{rad}, \mathrm{P}}}{\phi_{\mathrm{F}, 0} \tau_{\mathrm{rad}, \mathrm{M}}}\right)^{-1}\left(x_{\mathrm{M}}^{\prime} \frac{\left(C / C_{0, \mathrm{M}}\right)^{2} x_{\mathrm{P}} g\left(1-f_{\mathrm{P}, \mathrm{M}}\right)}{1+\left(C / C_{0, \mathrm{M}}\right)^{2} x_{\mathrm{P}} g\left(1-f_{\mathrm{P}, \mathrm{M}}\right)}+x_{\mathrm{P}}^{\prime}\right)$.

\section{References}

[1] M. Maeda. Laser dyes: properties of organic compounds for dye lasers (Academic Press, Tokyo, 1984).

[2] U. Brackmann, Lambdachrome laser dyes (Lambda Physik, Göttingen. 1986).

[3] Kodak laser dyes, Kodak. Publication JJ-169 (Eastman Kodak Company, Rochester. NY, 1987).

[4] Dye laser catalog (Exciton Inc., Dayton, OH. 1989).

[5] R. Steppel, in: CRC handbook of laser science and technology, Vol. I. Lasers and masers, ed. M.J. Weber (CRC Press, Boca Raton, FL, 1982) pp. 299.

[6] M. Michailidi, Y. Budansky, X.M. Zhao, Y. Takiguchi and R.R. Alfano, Opt. Letters 13 (1988) 987.

[7] V. Petrov, M. Wittmann, W. Bäumler and A. Penzkofer, Opt. Commun. 95 (1993) 81.

[8] Th. Sizer II, J.D. Kafka, I.N. Duling III, C.W. Gabel and G.A. Mourou, IEEE J. Quantum Electron. QE-19 (1983) 506.

[9] J.M. Halbout and D. Grischkowsky, Appl. Phys. Letters 45 (1984) 1281.

[10] W. Dietel, E. Döpel, V. Petrov, C. Rempel, W. Rudolph, B. Wilhelmi, G. Marowsky and F.P. Schäfer, Appl. Phys. B 46 (1988) 183.
[11] W.H. Knox, IEEE J. Quantum Electron. QE-24 (1988) 388. [12] J.M. Drake, R.I. Morse, R.N. Steppel and D. Young, Chem. Phys. Letters 35 (1975) 181.

[13] M. Zhao, L. Zhu, Y. Qian and X. Tang, Chin. Phys. Lasers 14 (1987) 782.

[14] B. Comaskey, T. Daly, C. Haynam. J. Morris, J. Paisner and R. Young, in: Pulsed single-frequency lasers: technology and applications, eds. W.K. Bischel and L.A. Rahn, SPIE 912 (1988) 73

[15] K. Kurokawa. H. Kubota and M. Nakazawa, Opt. Commun. 68 (1988) 287.

[16] H. Kubota, K. Kurokawa and M. Nakazawa, Opt. Letters 13 (1988) 749.

[17] D. Doizzi, Bibliographic study of photophysical and photochemical properties of laser dyes, Centre d'Etudes Nucléaires de Saclay, CEA-R-5359 (June 1986).

[18] T.G. Pavlopoulos and D.J. Golich. J. Appl. Phys. 67 (1990) 1203.

[19] P.R. Hammond, J. Chem. Phys. 70 (1979) 3884.

[20] E.A. Dorko, K. O'Brien, J. Rabins and S. Johnson Jr., J. Photochem. 12 (1980) 345.

[21] Y. Lu and A. Penzkofer. Chem. Phys. 107 (1986) 175.

[22] A. Penzkofer, W. Leupacher, B. Meier, B. Runde and K.H. Drexhage, Chem. Phys. 115 (1987) 143. 
[23] Th. Förster, Fluoreszenz organischer Verbindungen (Vandenhoeck and Ruprecht, Göttingen, 1951).

[24] A. Penzkofer and Y. Lu, Chem. Phys. 103 (1986) 399.

[25] O.G. Peterson, J.P. Webb, W.C. McColgin and J.H. Eberly, J. Appl. Phys 42 (1971) 1917.

[26] S.J. Strickler and R.A. Berg, J. Chem. Phys. 37 (1962) 814.

[27] J.B. Birks and D.J. Dyson, Proc. Roy. Soc. A 275 (1963) 135.

[28] A. Penzkofer and W. Leupacher, J. Luminesc. 37 (1987) 61.

[29] Y. Lu and A. Penzkofer, Appl. Opt. 25 (1986) 221.

[30] K.H. Drexhage, Laser Focus 9, No. 3 (1973) 35.

[31] T. Karstens and K. Kobs, J. Chem. Phys. 84 (1980) 1871.

[32] T. Kubin and A.N. Fletcher, J. Luminescence 27 (1982) 455.
[33] R. Sens, Dissertation, Universität-Gesamthochschule Siegen (Siegen, 1984).

[34] E.D. Cehelnik, K.D. Mielenz and R.A. Velapoldi, J. Res. Natl. Bur. Std. 79A (1975) 1.

[35] F. Dörr, Angew. Chem. 78 (1966) 457.

[36] H.E. Lessing and A. von Jena, in: Laser handbook, vol. 3, ed. M.L. Stitch (North-Holland, Amsterdam. 1979) pp. 753.

[37] M. Ruck, in: Landolt-Börnstein, II. Band: Eigenschaften der Materie in ihren Aggregatzuständen, 8. Teil: Optische Konstanten, eds. H.K. Hellwege and A.M. Hellwege (Springer, Berlin, 1962) pp. 5-610.

[38] A.V. Deshpande, A. Beidoun, A. Penzkofer and G. Wagenblast, Chem. Phys. 142 (1990) 123. 